\title{
Novas Modulações do Controle Organizacional: um Estudo de Caso ${ }^{1}$
}

\author{
Cláudia Maria Perrone \\ Universidade Federal de Santa Maria, RS, Brasil. \\ Gênesis Marimar Rodrigues Sobrosa \\ Faculdade Murialdo, RS, Brasil.
}

\author{
Anelise Schaurich dos Santos \\ Universidade do Vale do Rio dos Sinos, RS, Brasil. \\ Lize Maria Cardoso Calvano \\ Universidade Federal de Santa Maria, RS, Brasil.
}

\begin{abstract}
Resumo: O poder nas organizações não se manifesta apenas por vias coercitivas na atualidade. Ele atua por meio de dispositivos de poder, nos quais são incluídos os métodos disciplinares, que operam diretamente na subjetividade do sujeito. Esses mecanismos tornam os trabalhadores reconhecíveis, identificáveis e comparáveis entre si. Este estudo objetivou explicitar parte dos resultados de uma pesquisa sobre controle organizacional e subjetividade no contemporâneo. A pesquisa referida investigou a lógica pós-disciplinar presente nos mecanismos de controle organizacional por meio da problematização do nexo entre tecnologia e subjetivação. Os resultados apresentados neste trabalho são relativos a uma parte da amostra total, composta de trinta sujeitos. Foi escolhido o caso de uma mulher, funcionária de uma instituição financeira transnacional, configurando este artigo como um estudo de caso. Os resultados do estudo de caso apontaram que a lógica vigente da organização do trabalho obriga que o trabalhador assuma para si as flutuações da demanda, bem como a responsabilidade dos resultados. Dessa forma, há indicativos que as novas formas de organização do trabalho possibilitam a autorresponsabilização do sujeito.

Palavras-chave: Organizações, Poder, Trabalho, Subjetividade, Estudo de Caso.
\end{abstract}

\section{New modulations of organizational control: a case study}

\begin{abstract}
The organizational power is not manifested only by coercive ways nowadays. It operates through power devices, including disciplinary methods, which operate directly on the subjectivity of the subject. These mechanisms make workers recognizable, identifiable and comparable among each other. This study aimed to clarify part of the results of research on organizational control and subjectivity in contemporary. Referred survey investigated the post-disciplinary logic present in organizational control mechanisms by questioning the link between technology and subjectivity. The results presented in this paper are relative to a portion of the total survey sample, composed by thirty subjects. The case of a woman employee of a transnational financial institution was chosen, setting this article as a case study. The results showed that the current logic on organization of work requires workers to assume the demands and the responsibility of results for themselves. Thus, there are signs that new forms of work organization enable the self-empowerment of the individual.
\end{abstract}

KeYwords: Organizations, Power, Work, Subjectivity, Case Study.

\footnotetext{
${ }^{1} \mathrm{O}$ presente artigo apresenta parte dos resultados da pesquisa intitulada "O controle na sociedade de controle: a nova economia afetiva das organizações”, realizada com o apoio do Conselho Nacional de Desenvolvimento Científico e Tecnológico (CNPq), de acordo com o Edital Universal CNPq Processo nº 401590/2011-9.
} 


\title{
Nuevas modulaciones del control organizacional: un estudio de caso
}

\begin{abstract}
Resumen: Actualmente, el poder en las organizaciones no se manifiesta exclusivamente por vías coercitivas. Este actúa mediante dispositivos de poder en los que se incluyen los métodos disciplinarios, que operan directamente en la subjetividad del sujeto. En este sentido, estos mecanismos tornan a los trabajadores reconocibles, identificables y comparables entre sí. Este estudio tuvo como objetivo explicitar parte de los resultados de una investigación sobre control organizacional y subjetividad contemporáneos. Dicha investigación buscó comprender la lógica pos-disciplinaria presente en los mecanismos de control organizacional mediante la problematización del vínculo existente entre tecnología y subjetivación. Los resultados presentados en este artículo se relacionan con una parte de la muestra total de la investigación, compuesta por treinta sujetos. Se eligió el caso de una empleada de una institución financiera transnacional, siendo este artículo un estudio de caso. Los resultados del estudio de caso mostraron que la vigente lógica organizacional del trabajo obliga al trabajador a asumir las fluctuaciones de la demanda y la responsabilidad de los resultados. De esa manera, hay indicios de que nuevas formas de organización del trabajo posibilitan la propia responsabilidad del sujeto.

Palabras clave: Organizaciones, Poder, Trabajo, Subjetividad, Estudio de Caso.
\end{abstract}

O objetivo deste estudo foi investigar a lógica pós-disciplinar presente nos mecanismos de controle organizacional por meio da problematização do nexo entre tecnologia e subjetivação. O poder das organizações não opera somente por meios coercitivos explícitos, mas na montagem de um dispositivo de poder que inclui métodos disciplinadores (recrutamento, seleção, profissionalização, treinamento permanente), os quais agem nos processos de subjetivação dos indivíduos, tornando-os reconhecíveis, identificáveis, comparáveis e calculáveis. Parte-se do pressuposto de que essa investigação pode identificar traços do que pode ser denominado de sujeito neoliberal.

Michel Foucault (1979a) antecipou em seu livro "O Nascimento da Biopolítica" a ideia de que o neoliberalismo não era somente uma ideologia a favor dos mercados e do capital financeiro. O neoliberalismo é um conjunto de práticas teóricas, técnicas, políticas, estatais e institucionais que apontam para a invenção de um novo sujeito. Distintos dispositivos organizam esse sujeito para conceber a si mesmo como empreendedor, como um empresário de si, entregue a maximização de sua produção e rendimento. A partir dessas ideias, será apresentado um estudo de caso que tenta compreender aspectos desse sujeito nascente.

\section{Controle organizacional no capitalismo contemporâneo}

Háumlongo percurso histórico na associação entre organização e controle, termos indispensáveis para o entendimento do sujeito na atualidade. Essa ligação é um dos modos de falar em conhecimento-poder no contemporâneo. A pesquisa sobre o assujeitamento no trabalho envolve uma breve tipificação sobre a relação poder e controle, a qual possui múltiplas discussões, desde orientações tipológicas e históricas (Burawoy, 1983; Edwards, 1979; Mintzberg, 1992) até as descrições de características do controle associadas a determinadas formas organizacionais (Burawoy, 1979; Dore, 1973; Lincoln, \& Kalleberg, 1990).

O controle organizacional também é visto sob diferentes perspectivas (Lincoln, \& Kalleberg, 1990). A orientação marxista segue um caminho historicista para descrever as formas de controle organizacional que se desenvolveram na história das organizações. Edwards (1979) estabeleceu três tipos: (1) o controle simples ou hierárquico, baseado na supervisão direta, iniciado no século 19; (2) o controle tecnológico, obtido com o fluxo contínuo de produção, tipicamente taylorista; (3) o controle democrático, que se organiza ao redor da imposição impessoal de um sistema normativo, que iniciou ao redor dos anos 50 do século passado. Buroway (1979) apresentou uma 
divisão entre dois regimes industriais, um que enfatiza a coerção e outro, o consentimento. É preciso considerar, ainda, a perspectiva weberiana, a qual pensou a organização do trabalho capitalista como uma forma de controle por meio da legitimidade e racionalidade da norma organizacional.

A literatura sobre controle explorou pouco as ideias de Foucault $(1975,1980)$ e Deleuze (1992) acerca do poder, desenvolvidas posteriormente pelos teóricos da governamentalidade (Gordon, 1991). Foucault (1975) considerou que a sociedade moderna estava baseada predominantemente no poder disciplinar, que perseguia a obediência dos corpos a partir do adestramento e do castigo corretivo. Ele citou explicitamente a fábrica como uma instituição disciplinar. Seguindo esse entendimento, Deetz (1992) defendeu que o poder disciplinar pertence à origem mesma da organização moderna.

No pensamento de Foucault (1975), podem-se distinguir três aspectos do poder disciplinar (Danaher, Schirato, \& Webb, 2000). O primeiro é o panóptico, baseado na possibilidade de estar sempre submetido à vigilância. O segundo é o adestramento, um processo de normalização e submetimento dos corpos a determinadas atividades e saberes que resulta na classificação dos sujeitos de acordo com seu desempenho. O terceiro é a autodisciplina, o esforço para alcançar um estado idealizado de perfeição individual a partir de critérios determinados por instâncias externas ao sujeito.

A via aberta por Foucault (1975) tornou possível vincular o poder disciplinar foucaultiano com o controle organizacional, por meio da articulação proposta por Deleuze (1992) na Sociedade de Controle. O novo controle da Sociedade de Controle é exercido por meio de uma série de práticas que buscam o governo dos sujeitos e sua aprovação dos processos organizacionais, o que produz diferentes modos de disciplinamento. Ao tomar como ponto de partida a lógica da sociedade de controle proposta por Deleuze (1992), é possível investigar e estabelecer uma série de mecanismos de controle organizacional que produzem processos de governo dos sujeitos.

Destaca-se que as organizações contemporâneas transformaram-se substancialmente (Kalleberg, 2000; Powell, 2001), gerando novas relações de trabalho (Kalleberg, 2000) e novas formas de organização do trabalho impulsionadas pelas inovações tecnológicas no campo da gestão da informação, o que possibilitou a instalação de novos dispositivos de controle sobre os trabalhadores. Novas lógicas organizacionais engen- dram lógicas disciplinares que podem estar representadas por antigos mecanismos de controle.

Outro aspecto relevante a ser pensado na relação entre o pensamento de Foucault (1979b, 1999) sobre o poder e o controle organizacional é o aspecto positivo do poder. Esse produz novas formas de vida e diferentes formas de gestão de vida. O objetivo é utilizar ao máximo as potencialidades do sujeito, ao mesmo tempo em que incita e define um sistema de aperfeiçoamento gradual e contínuo de suas capacidades (Foucault, 1979b).

Yela Goméz e Hidalgo Romero (2010) realizaram uma revisão dos argumentos teóricos que utilizam o pensamento foucaultiano na análise das organizações e concluíramqueaindaprevaleceumanoçãoeumaproblematização do poder instrumental (poder-ferramenta), que dá suporte e legitimidade às práticas organizacionais vigentes, e da relação poder/organização como um universo autônomo. Essa ideia é legitimada pelas teorias organizacionais que garantem a universalização teórica das organizações, o que oblitera o fato que a dinâmica organizacional é parte essencial da sociedade capitalista e oculta traços históricos concretos dessa sociedade (Buroway, 1979).

No entanto, é possível realizar outras articulações, não universalistas, da obra do filósofo, que se organizam a partir dos processos de subjetivação. A perspectiva de Foucault remete à lógica da relação entre poder e subjetividade (Yela Goméz, \& Hidalgo Romero, 2010), na qual o sujeito se constitui a partir das relações entre saber-poder. O exercício do poder determina e é determinado pela subjetividade do indivíduo. Nesse sentido, a forma do poder é o assujeitamento, que articula o social e o sujeito para a criação de uma "subjetividade autodisciplinada" (Knights, \&Willmott, 2007) em que o exercício do poder pressupõe a liberdade. O sujeito não é obrigado, mas incitado a participar e, no exercício das práticas, sente segurança e pertencimento (Montes Cató, 2005).

A questão das práticas remete, ainda, às articulações com as tecnologias de si e de governamentalidade. Para Zangaro (2010), as formas de gestão do trabalho constituem um articulador das práticas de subjetivação, que propõem modos de ação sobre si mesmos aos sujeitos. A gestão articula um dispositivo de saber-poder-governo por meio das práticas, as quais produzem a subjetividade implicada em que os próprios trabalhadores controlam o uso eficiente da força de trabalho a favor dos objetivos do capital (Zangaro, 2010).

A nova lógica disciplinar do pós-fordismo define-se por situar no sujeito a responsabilidade 
pelo seu desempenho, a partir de um mecanismo de autoavaliação e regulação constante, o que caracteriza a autodisciplina. Crespo, Revilla e Serrano (2006) denominam esse fenômeno como sujeição moral ou autossujeição, pois se realiza por meio de critérios não definidos pelo sujeito, mas pela organização em função de seus interesses e metas, mesmo que o sujeito, ao subjetivar-se nessa lógica, não reconheça a determinação organizacional desse funcionamento.

A nova lógica do controle possibilita a descrição de mecanismos externos ao sujeito. O controle concertivo (Barker, 1993) ou normativo (Barley, \& Kunda, 1992), exercido de modo mais ou menos consensual pelos membros de um grupo, constitui uma vigilância entre iguais (Sewell, 1998) por meio do exercício do "olhar panóptico" (Sewell, \& Wilkinson, 1992) que garante a autoadministração. Boltanski e Chiapello (1999) denominaram de controle mercantil a dependência gerada diretamente por um cliente. $\mathrm{O}$ aprofundamento deste controle levou Dubar (2002) a considerar uma das características do mundo do trabalho atual a extensão das relações de serviço às relações de produção.

Outro tipo de controle, denominado controle por resultados, reside na fixação de objetivos de produção a serem alcançados em um determinado prazo de tempo, que resultarão em benefícios econômicos. Essa situação, no seu limite, pode chegar até a desaparição do vínculo identitário organizacional em favor de um contrato mercantil, o qual estabelece uma relação de serviço entre o trabalhador e a organização ou clientes. Esse seria o controle mercantil, pois o sujeito se disciplina e dirige seu comportamento laboral em função de sua percepção e compreensão das demandas do mercado. É a dívida infinita apontada por Deleuze (1992), na qual é preciso estar sempre atualizado para garantir a empregabilidade, para nunca ficar para trás.

O mercado torna-se um instrumento disciplinar que legitima demandas para o trabalhador. A ausência da estabilidade, que resulta da flexibilidade e da precariedade das relações de trabalho, constitui também uma forma de disciplinamento. Éuma lógica da fluidez (Bauman, 2000), na medida em que é produzida exatamente pela ausência da permanência dos critérios e normas de funcionamento. É causada pela repetição da mudança, de forma aparentemente caótica, dos critérios e normas de funcionamento da organização, o que gera um grau elevado de dificuldade para o trabalhador organizar a sua tarefa ou simplesmente permanecer na organização. É o controle do pós- fordismo com a sua lógica de flexibilização de todos os processos produtivos. A flexibilidade ainda produz a instabilidade que move os trabalhadores a reafirmar continuamente seu compromisso com os valores do sistema e aceitar disciplinadamente a precariedade (Alonso, \& Fernández, 2009).

Ressalta-se que os novos referenciais, entre outras questões, trazem um debate sobre a eventual ruptura dos novos modelos organizacionais com a tradição taylorista-fordista, um dos pilares da produção capitalista. O desafio hoje é controlar e disciplinar a subjetividade dos trabalhadores. A mesma ideia já foi afirmada por Boltanski, e Chiapello (1999, p. 25), ao relatarem que o objetivo é "transportar as pressões da exterioridade dos dispositivos organizacionais para a interioridade das pessoas". Nesse sentido, não há exatamente uma superação, mas a utilização concomitante de meios que abrangem mecanismos disciplinares característicos do taylorismo (Stecher, Godoy, \& Toro, 2010) - como ordenação do tempo, do espaço, do ritmo de trabalho - com a modulação (Deleuze, 1992) flexível da subjetividade.

A noção de modulação em Deleuze (1992) pode ser identificada na forma como são utilizados os atributos cognitivos dos trabalhadores. A modulação traz a ideia da implicação da inteligência e da criação dos sujeitos como elementos essenciais da produção. Essa relação e o caráter de continuidade e intensificação entre taylorismo/fordismo e pós-fordismo pode ser caracterizada pela fórmula de produção "minimax" (Blanch-Ribas, 2003): obter o máximo aproveitamento do tempo de trabalho para atingir metas de produção cada vez mais elevadas e, concomitantemente, conseguir que os trabalhadores interiorizem a responsabilidade pela qualidade de produtos e serviços.

Otrânsito doparadigmaprodutivotaylorista-fordista para o regime de acumulação flexível também foi problematizado por Stecher et al. (2010), não como modulação, mas como flexibilização, o principal mecanismo de adaptação e maximização do capital ligado aos fluxos globais. O contraste entre a rigidez do taylorismo e o capitalismo flexível não define uma oposição, mas uma relação de confluência, de coexistência em tensão das diferentes lógicas.

Stecher (2009) também aponta um elemento importante para pensar as implicações do sujeito como "gestor de si". O novo sistema flexível de produção implica na radicalização do processo individualista. Cada um realiza a gestão reflexiva de sua identidade 
em meio a exigências altamente contraditórias. Cada sujeito constrói narrativas identitárias com certa continuidade e orientação das ações, com ganhos em sua autonomia. No entanto, sofre intensa pressão normativa, resultado do novo controle flexível.

\section{Método}

Utilizou-se, para realizar a pesquisa sobre o controle organizacional, o método qualitativo. O procedimento de pesquisa utilizado foi o estudo de caso, que tem valor crucial para abarcar a complexidade de compreender as mudanças relacionadas à subjetividade e à economia afetiva, provocadas pelo uso intensivo da tecnologia e o controle organizacional, pois ele é um articulador entre o singular e o universal (Pedinielli, \& Fernandez, 2011).

Este caso foi escolhido no universo de uma pesquisa maior sobre controle organizacional devido ao seu caráter revelador, pois conseguiu sintetizar as principais características encontradas no universo abordado. $\mathrm{O}$ estudo de caso possibilitou sistematizar e destacar dados de modo aprofundado e exaustivo, os quais se tornaram difíceis de destacar em uma interpretação unificada dos inúmeros aspectos do universo do controle organizacional estudados na pesquisa maior. Foi escolhido o caso de uma mulher, funcionária de uma organização transnacional, pertencente a um setor que opera a partir da materialidade sociotecnológica e organizacional, problematizada na teorização sobre a sociedade de controle e o trabalho imaterial. Essa participante possuía relações formais de trabalho e estava na organização há seis anos.

A coleta de dados foi realizada por meio de entrevistas individuais semiestruturadas com o objetivo de entender a rotina de trabalho, de vida e o entendimento do sujeito relativo ao controle organizacional. O objeto principal da utilização de entrevistas diz respeito à obtenção de informações a partir da reflexão do próprio sujeito sobre a realidade que vivencia (Minayo, Deslandes, \& Gomes, 2007). As entrevistas foram gravadas e posteriormente transcritas na íntegra. Segundo Bauer e Gaskell (2002, p. 78), as entrevistas individuais são recomendadas, dentre outras situações, "quando o tópico se refere a experiências individuais, detalhadas, escolhas e biografias pessoais" ou para abordar "assuntos de sensibilidade particular que podem provocar ansiedade". As entrevistas ocorreram fora do local de trabalho, em local indicado pelo entrevistado ao longo do ano de 2013.
Para tratar os dados coletados, foi realizada sua análise qualitativa. Eisenhardt (1989) destaca que não há um padrão ou formato de análise de dados em pesquisas conduzidas por meio do procedimento do estudo de caso. Yin (2005) indica que a estratégia de análise dos dados é baseada na análise das proposições teóricas, organizando o conjunto de dados com base nas mesmas e buscando evidências das relações propostas na teoria.

Destaca-se que a pesquisa foi submetida e aprovada pelo comitê de ética da universidade responsável pelo estudo, tendo sido observados os preceitos e procedimentos éticos previstos na Resolução no 466/12 do Conselho Nacional de Saúde (Brasil, 2012), a qual regulamenta a realização de pesquisas com seres humanos. Teve-se o cuidado de proteger os participantes e evitar qualquer risco que o estudo pudesse causar. Os indivíduos foram informados sobre os objetivos do estudo, do caráter voluntário da pesquisa, bem como sobre o sigilo em relação às informações coletadas e o anonimato em relação as suas identidades. Foi entregue aos participantes interessados em integrar a amostra do estudo o Termo de Consentimento Livre e Esclarecido (TCLE) para que formalizassem a sua participação na pesquisa ao assiná-lo.

\section{Caso P.: ascensão e queda de uma funcionária exemplar}

Analisaram-se os dados fornecidos por P., uma mulher de trinta anos, com formação universitária, que solicitou demissão de sua organização transnacional há dois meses. Essa organização sofreu a maior crise de sua história de 190 anos há quatro anos. A sua unidade no Brasil é considerada de importância estratégica. No entanto, o grupo sofreu um processo de desmembramento e venda de ativos para seguir operando.

Não foi descartada, ainda, a venda da unidade brasileira, pois o lucro da organização em 2012 foi negativo em relação a 2011. A empresa possuía 5.911 funcionários no Brasil e a matriz no exterior está sofrendo processos de fusão. No Brasil, possui ativos de US $\$ 40$ bilhões, mas recentemente suas ações sofreram baixas de 4,68\%. Novos executivos recentemente contratados afirmam que a missão da operação brasileira é devolver ao grupo seu prestígio e torná-lo relevante para os clientes nacionais. A empresa opera com comércio exterior e investiu US $\$ 1$ bilhão em uma plataforma tecnológica e está integrando seus sistemas. Nesse momento, a organização está voltada menos para a conquista do mercado e mais para a reconquista de seus clientes. 
P. trabalhou durante quatro anos e meio como gerente de expansão. Ela ingressou na organização como gerente de atendimento e atendia no Serviço de Atendimento ao Consumidor (SAC) da empresa, no qual ficou um ano e meio. Sentiu muita dificuldade nessa mudança, pois a sua atividade anterior "era mais previsível, todas as atividades eram previstas com certos protocolos". A mudança ocorreu quando houve a reestruturação da organização e P. não entendeu muito bem qual foi a lógica de ser promovida para o novo cargo: "Eu quis saber, mas não ficou muito claro. Fico pensando se era claro para eles também. Recebi algumas explicações sobre o meu perfil, como me sai bem no cargo anterior. Todos querem subir, o salário seria melhor, por que não?". Insistiu-se em perguntar se ela não identificava motivos para sua mudança: "Eu investi muito na minha formação. Tenho dois MBAs, em finanças e gestão de pessoas. Eu estava pronta para novas funções na empresa, eu assumia muito a empresa, mas não pensei que seria assim".

Ela sentiu as mudanças rapidamente. A remuneração na nova função era variável e P. recebia os adicionais somente após três meses, se houvesse a consolidação da relação com o cliente. As cotas eram vinte novos negócios mensalmente, uma meta alta que exigia "trabalho intenso, nada como a previsibilidade da outra função". Sobre perceber as mudanças:

O mais difícil não foram as exigências iniciais. Era meio difícil de entender o que estava acontecendo. Eu achava que era, sei lá, uma adaptação. Eu achava que era um tempo, precisava de um tempo para me adaptar as mudanças e depois tudo ficaria normal. Acho que comecei a entender melhor a situação quando teve a troca do gestor. Falaram que receberíamos o líder, não era um cara qualquer. A situação estava complicada, unidades fechando, os negócios diminuindo. A ideia é que os que sobraram não eram qualquer um, eram os melhores. Foi isso que imaginei. Mas não foi assim.

No âmbito das relações de trabalho, destaca:

O meu gestor anterior era uma pessoa educada. A impressão que eu tinha era de que ele era uma pessoa do nosso lado, ele estava do nosso lado. Eu sei que não era assim, mas ele, sei lá... Entendia o que acontecia conosco e assim era melhor. Parece que fica mais humano. Porque era essa a primeira diferença. Pensei que encontraria o líder, o cara inspirador. A primeira coisa, na primeira reunião, foi que achei ele um grosso. $\mathrm{O}$ discurso era aquele, motivação, porque vocês acham que estou aqui? Sabe, e aí aquelas coisas: alguém aqui quer folga? Se quer folga pode sair, pode ir embora.

Nesse momento da entrevista, P. agita-se, não olha mais para a entrevistadora, mas para o chão.

Eu não entendi, sabe. Eu achava o cara muito grosso, com brincadeiras sem graça. Custei um pouco para me dar conta que ele agredia com isso, ele chegava perto demais, aquela história do espaço de cada um, ele invadia, dava tapinhas sem necessidade. Mas tudo era motivacional.

No âmbito da compreensão do curso dos acontecimentos relacionados à situação da empresa:

A situação da empresa estava pior, ou não, não sei. Mas os negócios estavam realmente diminuindo e tudo começou a ficar pior. Aconteceu outra mudança. Nós tínhamos um celular da empresa e cada um tinha também o seu celular particular. Quando esse cara chegou, ele pediu os celulares particulares. Quando eu ia para a casa do meu namorado, eu desligava o celular da empresa. Mas alguém poderia querer falar comigo, minha mãe. Então eu deixava o meu celular ligado. Sabe o que começou a acontecer? Começaram a chegar as mensagens e algumas lembranças no celular privado, as seis e vinte da manhã ou a meia-noite. Tenho aqui as mensagens, não apaguei (mostra para a entrevistadora). Estou vendo aqui, olha (mostra no celular). Essa é a que chegou mais cedo, cinco e cinquenta e cinco da manhã. Quer ver? Olha só o que ele escreveu: "não se poupem".

Sobre o motivo de não ter apagado as mensagens:

Não sei, não sei bem, talvez lembranças. Nosso horário também complicou. Não recebíamos hora extra. Todo mundo começou a trabalhar mais, a ficar mais na empresa. 
E o cara sempre gritando: alguém pensa que hoje é feriado? Era grosso isso e esse não é o nosso ambiente e nem o dos nossos clientes, era muito fora tudo aquilo. Mas eu comecei a não querer ficar mais tempo. Nossas viagens também aumentaram, visitas.

P. foi questionada sobre como lidou com essa situação.

Questionei, mas era a única. O cara me chamou de muito sensível, se eu não estava entendendo que isso era motivação. Estávamos no meio de uma guerra. Eu respondi: não é guerra nada e nem motivacional, é pé no saco mesmo. E sabe o pior? Tinham superiores ali, eles ouviram e eu sabia que eles não pensavam assim, mas não fizeram nada. Ou fizeram, uma conciliação, gestão de conflito.Questionei até o porquê escolheram esse cara. Disseram que ele tinha clientes bons. Sabe o que era clientes bons? Gente falida, não tinha como. Eu conhecia a realidade financeira dos clientes, sabia que para alguns era corda para se enforcar e me dei conta que meu cargo anterior era de proteção aos clientes. Eu comecei a ter um sofrimento, sei lá, acho que ético. O negócio que eu ia fechar, quando fechava porque era blefe, o cara não tinha clientes novos, ia ferrar com as pessoas. É mau negócio, bom para a empresa, mas ia ser o fim do cara.Teve outra mudança também. Começamos a receber pela intranet um quadro atualizado diariamente com o desempenho de negócios de cada pessoa. No final do dia já dava aquele mal-estar para saber onde ficaríamos, bem ou mal na colocação. Mais os e-mails "motivacionais": estamos na reta final. Eu pensava no outro gestor, a gente tinha controle sobre nós, mas era um controle saudável. A minha meta era $\mathrm{R} \$ 400.000,00$ por semana com aqueles clientes. Eu me dava bem, apesar de tudo. Não era esse o problema. Era outra coisa, era essa coisa ética, eu tava ferrando, sabia que ia ferrar muitos clientes. Mas eu me dava bem, não foi por aí. Um momento eu pedi para sair. Não sei bem como foi. Eu me irritei muito também porque tinha isso do espaço, o cara invadia. Segunda-feira era cheio de piadinhas, sobre o que ele tinha visto no Face [rede social] de cada um. As pessoas não acreditavam, mas comecei a falar. Olha, ele me perguntou sobre surf, eu tava na praia. Para outro veio com papo de pizzaria, tinha a ver com Face. Ele queria mostrar que sabia de tudo, controlava tudo. Comecei a perceber que eu não tinha mais assunto, eu só falava de trabalho. O meu namorado queria falar comigo sobre a vida dele, o que acontecia e eu não deixava, era só eu falando do meu trabalho, do que acontecia. Eu ficava muito irritada, cada vez mais irritada com tudo e por nada. Começamos a brigar mais, mas eu comecei a ficar ansiosa, não queria ficar sozinha. Isso foi ficando pior, pior. Fui ao médico e recebi o diagnóstico de Síndrome do Pânico. Mas aí me dei conta que eu não conseguia nem pedir demissão, não conseguia. A médica me disse que eu precisava de uma licença de saúde. Sabe para quê? Para conseguir pedir demissão, para chegar lá e fazer isso, para ficar forte para poder sair. Eu não percebi.

P. foi questionada sobre porque acha que não percebeu.

Acho que foi o dinheiro, ganhei muito dinheiro. Mas não adianta. Voltei, negociei minha saída e muitas pessoas disseram que também iriam se demitir. Falaram que eu deveria ir fazer alguma coisa. Ninguém saiu e eu disse que quem ficasse lá que fizesse alguma coisa. Já estou meses sem trabalhar. Não consigo ganhar tanto como ganhava lá, é difícil. Mas alguma coisa vai aparecer. Ainda estou me tratando, já passou muita coisa. Tenho muita ansiedade. Às vezes, parece que não vou dar mais conta, mas acho que ainda vai passar.

\section{Resultados e discussão}

A análise será centrada nas mudanças e nas exigências dos diferentes mecanismos de disciplinamento e controle que operam na vida de P. Seguindo a proposta de Deleuze (1992) e Foucault (2010), são chaves analíticas importantes: vida, trabalho e política. Isso para compreender as novas formas de controle, cuja ancoragem é a subjetividade.

P. era uma funcionária com perfil multifuncional e polivalente. Ela iniciou a sua carreira na empresa em outra área e função e não foi uma escolha 
pessoal a sua ida para outra área da empresa. Ela era uma profissional preocupada com a sua formação e investiu no seu aperfeiçoamento, mantendo a expectativa de mudança dentro da organização. Uma "mão invisível" realizou a avaliação de P. e a indicou para a nova função. A sua avaliação passou pela observação de suas condutas e modos de reagir frente a fatos reais, como ela resolveu certas situações dentro de uma situação concreta e sua disponibilidade para isso. Mesmo que faça referência ao fato de "assumir a empresa", P. não tem clareza sobre o fato de que foi avaliada no seu "saber-fazer", mas também em "saber-ser" em relação a valores afetivos da organização. O que estava posto no momento em que ela realizou a troca de cargos é que ela foi considerada uma funcionária que incorporou um modelo de comportamento que correspondia com a ordem normativa proposta pela empresa, pronta para o envolvimento afetivo e emocional que a organização propunha.

Pode-se dizer que a saída de P. do SAC da organização para o novo cargo correspondeu a sua passagem de funcionária da organização para a "empresária de si mesmo". Nessa passagem, ela deveria ser capaz de interiorizar os "novos valores e a nova ética" empresarial que se apresentou desde o momento inicial como contraditória em relação a sua identidade prévia com a empresa. No cargo anterior, P. localizava a existência relacionada com um coletivo de trabalho, com certa solidariedade e fraternidade com os colegas e, principalmente, com a sua chefia.

Foram eleitos uma série de dispositivos que pretendiam trabalhar para desmontar e inibir a identidade anterior de P., encaminhando-a para uma gestão individual e de profunda solidão. As "dificuldades" encontradas na nova função foram tratadas por meio da gestão de conflito pessoais de uma trabalhadora particular com a sua nova liderança. O novo líder da equipe também foi descrito como "grosseiro e mal-educado".

O caráter supra-individual das relações foi negado e ocultado pela promoção do indivíduo como ator privilegiado da organização, em benefício da produção de controle social e disciplina no trabalho. O conflito de P. foi atrelado a características pessoais, como sua excessiva sensibilidade e a falta de entendimento a respeito das intenções do líder. Esse discurso reforçou a omissão do aspecto organizacional da situação e localizou toda a responsabilidade do problema à incapacidade de P. em se adequar na nova lógica. $P$. também relatou um processo de fragmentação do tecido das relações sociais, com o aprofundamento do processo de individualização no qual ela foi colocada como responsável exclusiva pela dinâmica de trabalho. P. buscou resolver a nova situação de trabalho com autocontrole ou mais confiança, seguindo a ideia do empresariado de si e a sua gestão individualizada das relações de trabalho. Seria esperado que P. definisse um ajuste com seu novo líder e garantisse certa eficácia normativa e o ajuste ético e comportamental de sua nova função.

O processo de fragmentação do coletivo e isolamento estabeleceu para P. o "paradigma do medo" em suas múltiplas faces: medo do desemprego, medo da sua perda de competência, medo do outro. Rodriguez (2006) apontou este efeito de impor o medo e a suspeita para com qualquer outro como um exercício de controle e dominação. O outro se torna um suspeito, é sempre uma ameaça. A ultraindividualização converte a subjetividade em uma experiência de medo, pois o outro no mundo capitalista será sempre percebido como um lugar inadequado. A função da cultura do medo pode ser entendida a partir das considerações de Foucault $(2008,2010)$. Ele descreveu o liberalismo como uma arte de governo que manipula interesses, mas que também deve administrar os perigos que colocam em risco os seus interesses. Produz-se uma invasão de perigos cotidianos, sempre reanimados e reatualizados, e finaliza concluindo que não há liberalismo sem a cultura do perigo e do medo. A teoria do capital humano pensado por Foucault (2008) pode ser aproximado do "modelo das competências" e possibilita que o indivíduo se veja compelido a assumir seu corpo como um empresário que gestiona os recursos de que dispõe para produzir. "Formar capital humano" implica investimento constante para a melhor inserção no mercado.

P. também descreveu um mecanismo de autocontrole no uso de redes sociais. Mostrou certo estranhamento com o fato de seu líder sempre comentar suas postagens após o final de semana, o que deixou claro o seu olhar panóptico. No relato de P., acompanha-se a narrativa do desenvolvimento de uma tolerância entendida como uma capacidade de suportar as medidas de controle sem rechaço ou repúdio e esse é um fator dependente do tempo, que aumenta exponencialmente com o passar do mesmo. O processo de interiorizar o controle ataca e debilita a oposição ao mesmo. P. desenvolveu tolerância à ideia de ser controlada, criando um desajuste entre o controle real 
a que se está submetido e o controle percebido, reduzindo a possibilidade de oposição à vigilância.

O controle tecnológico não foi reconhecido claramente por P. Provavelmente, um dos fatores que dificulta essa localização é o fato da tecnologia ser parte essencial, é o instrumento para a realização das tarefas, ao mesmo tempo em que ocorre o registro em tempo real de todo o processo de trabalho. A tecnologia concede uma forma onipresente ao controle, principalmente nas tarefas que implicam mobilidade por meio dos dispositivos móveis, GPS, celulares. P. entendeu que o aspecto tecnológico do controle é "motivacional", ainda que reconhecesse o caráter de excesso presente na sua vivência.

Outro elemento que realiza um controle organizacional por meio de normas formais e racionais, que servem tanto para a organização do trabalho quanto para estabelecer relações sociais hierarquizadas, trata-se da burocracia que Max Weber (1992) entendia como a forma essencial do poder na época moderna, enfatizando os seus aspectos de racionalidade, previsão, impessoalidade. A formalização reveste-se de uma nova forma tecnológica, que consiste em organizar ao máximo o movimento dos trabalhadores. O controle ocorre simplesmente porque os trabalhadores seguem as regras de funcionamento da organização, sendo que essa formalização, em parte, é um substituto formal da supervisão direta (Robbins, 2005). P. aceitou todas as formalizações propostas pela organização, inclusive no momento de seu desligamento. Certamente, P. reconheceu uma conotação positiva, porque implicou em estabilidade e previsibilidade em um ambiente instável.

Na narrativa de P., observa-se como há a confluência do controle tecnológico com o de resultados. A produtividade do trabalho se transforma em um mecanismo disciplinar, uma autorregulação do comportamento para que sejam alcançados determinados resultados produtivos. O controle por resultados consiste no disciplinamento dos trabalhadores também devido à presença de incentivos financeiros, pois esses normalizam o prolongamento da jornada de trabalho, a disponibilidade, a autorresponsabilização pelo rendimento. Uma questão importante é a da determinação dos objetivos, pois eles são fixados em um nível crescente e desafiador para serem alcançados, o que produz uma pressão constante sobre os trabalhadores. Eles ainda sofrem o controle associado ao cliente, uma disciplina que os trabalhadores precisam desenvolver diante das demandas constantes dos clientes e coloca a relação de trabalho como um serviço mais do que produção. A relação com os clientes também trouxe um novo sofrimento para P., que ela chamou de ético.

O controle do mercado manifesta-se como a regulação da conduta no sentido de que uma exigência de adaptação constante ao mercado, de uma gestão de informação para tomada de decisão correta para manter-se e prosperar no mercado. P. descreve-se como uma funcionária que tem total responsabilidade sobre o resultado produzido, que assume como necessário e autoimposto, levando a situações de forte autoexploração. Essa é outra face da regulação pós-fordista com sua lógica líquida regida pela instabilidade e incerteza. $\mathrm{O}$ trabalhador deve a cada dia dar o melhor de si em um movimento de adaptação permanente.

Há ainda o controle que parte da demanda dos iguais, um controle relacional. Nesse, existe intensa pressão nos grupos de trabalho para que o trabalhador ajuste a sua conduta ao que acredita ser a expectativa de seus colegas de equipe. Esse controle tornase mais importante a partir do momento em que as organizações fazem uma responsabilização grupal sobre os resultados produtivos. O controle realiza-se por meio do tipo de vínculo que se estabelece nas equipes de trabalho. Para atingir as metas de produtividade, os trabalhadores devem ser capazes de gerar uma dinâmica grupal e interpessoal positiva, baseada na cooperação, confiança, solidariedade e requer um ajuste mútuo constante. A responsabilidade individual se dilui e o funcionamento em grande parte informal do grupo se encarrega de disciplinar e manter a realização das tarefas de forma adequada, seguindo a dinâmica que Sennett (2006) denomina de poder sem autoridade. Não é necessário ninguém, simplesmente a tarefa será realizada. Ressalta-se que o gerenciamento do trabalho torna-se a "gestão de si", não ocorrendo separação entre trabalho e vida, assim como a gestão de um é a gestão de outro.

\section{Considerações finais}

A conclusão de Deleuze (1992) de que o controle disciplinar na sociedade de controle não sofre uma descontinuidade, mas uma intensificação, mostra-se presente na narrativa de $\mathrm{P}$. Os novos modelos pós-fordistas de organização do trabalho não implicaram na ruptura com os modelos tradicionais e 
hierárquicos de autoridade, comando e controle. No entanto, eles tomaram a forma de um poder impessoal e obscuro, sustentado por um discurso democrático, participativo e humanizado.

A partir da narrativa de P., há indicativos de que os trabalhadores não estão totalmente conscientes desse controle, reagindo de modo punitivo e empobrecedor, tomando como falhas pessoais a não realização das metas e objetivos da organização. Reflexões sobre o caso apresentado incitam o pensamento que a lógica da organização do trabalho obriga os trabalhadores a assumirem pessoalmente as flutuações da demanda e a responsabilização dos resultados. As novas formas de organização do trabalho favorecem a autorresponsabilização do sujeito por resultados, assim como tendem a tornar invisível o poder da organização que se exerce sobre os sujeitos, sendo que o mercado ou o cliente exige a disponibilidade ou o prolongamento da jornada de trabalho.

Para P., também não fica clara a ausência de controle do sujeito sobre sua própria atividade na organização, pois esse é realizado por uma direção política e normas sempre em mudança e/ou arbitrárias. As fusões, aquisições ou reestruturações

\section{Referências}

Alonso, L. E., \& Fernández, C. J. (2009). Uso del trabajo y formas de governabilidad: laprecariedad como herramienta disciplinaria. In E. Crespo, C. Prieto, \& A. Serrano (Ed.), Trabajo, subjetividad y ciudadanía: paradojas del empleo em uma sociedad em transformación. Madrid: CIS-UCM.

Barker, J. R. (1993). Tightening the iron cage: concertive control in self-managing teams. $A d$ ministrative Science Quarterly, 38(3), 408-437. doi:10.2307/2393374

Barley, S. R., \& Kunda, G. (1992). Design and devottion: surges of rational and normative ideologies of control in managerial discourse. Administrative Science Quarterly, 37(3), 363-399. doi:10.2307/2393449

Bauer, M., \& Gaskell, G. (2002). Pesquisa qualitativa em texto, imagem e som. Petrópolis, RJ: Vozes.

Bauman, Z. (2000). Liquid modernity. Cambridge: Polity Press.

Blanch-Ribas, J. M. (2003). Trabajarenlamodernidad industrial. In J. M. Blanch-Ribas, \& C. Gala Durán empresariais produzem um essencialismo da mudança como um valor em si mesmo e cabe a $P$. ter conhecimento e habilidades para lidar e aceitar este novo estado de coisas.

Novas formas de controle organizacional implicam a alienação dos trabalhadores da fonte de poder. O cliente, o mercado, as metas de desempenho, a vigilância tecnológica são elementos mediadores entre o trabalhador e a organização. As organizações não contam apenas com a autodisciplina de seus trabalhadores. Elas fazem a gestão de dispositivos de controle que mobilizam o trabalhador ao mais trabalho (tempo e esforço) e dispostos a aceitar a mudança como valor fundamental. A alienação da fonte do poder dificulta a identificação de um responsável pelo controle de uma oposição. Uma das respostas encontradas é o assujeitamento/identificação, no qual desejam exercer sobre outros o que viveram ou uma reação semelhante ao Zizek (2012) chamou de proletariado libidinal, que o sujeito desenvolve uma "plasticidade destrutiva”, uma pós-vida após o apagamento da tessitura narrativa da identidade simbólica do sujeito, uma forma adquirida na destruição.

(Eds.), Teoria de lasrelacionaeslaborales: fundamentos (pp. 19-147). Barcelona: Editorial UOC.

Boltanski, L., \& Chiapello, E. (1999). Le nouvel esprit du capitalisme. Paris: Gallimard.

Brasil. Ministério da Saúde. Conselho Nacional de Saúde (2012). Resolução no 466/12, de 12 de dezembro de 2012. Estabelece diretrizes e normas regulamentadoras de pesquisa envolvendo seres humanos. Brasília, DF: o autor.

Burawoy, M. (1983). Between the labor process and the state: factory regimes under advanced capitalism. American Sociological Review, 48, 587-605.

Burawoy, M. (1979). Manufacturing consent. Chicago, IL: University of Chicago Press.

Crespo, E., Revilla, J. C., \& Serrano, A. (2006). La psicologización política deltrabajo. In A. Dorna (Ed.), Psicologia Política. Bogotá: Psicom Editores.

Danaher, G., Schirato, T., \& Webb, J. (2000). Understanding Foucault. Londres: Sage.

Deetz, S. (1992). Disciplinary power in the modern corporation. In M. Alvesson, \& H. Willmott, (Ed.), Critical management studies. Londres: Sage. 
Deleuze, G. (1992). Conversações. Rio de Janeiro, RJ: Editora 34.

Dore, R. (1973). British factory, Japanese factory: the origins of national diversity in industrial relations. Berkeley, CA: University of California Press.

Dubar, C. (2002). La crisis de las identidades: la interpretación de una mutación. Barcelona: Bellaterra.

Edwards, R. C. (1979). Contested terrain: the transformation of the workplace in the twentieth century. New York, NY: Basic Books.

Eisenhardt, K. M. (1989). Building theories from case study research. The Academy of Management Review, 14(4), 532-550. Recuperado de http://www.jstor.org/stable/258557

Foucault, M. (1975). Vigiar e punir.Petrópolis: Vozes.

Foucault, M. (1979a). O nascimento da biopolítica. São Paulo, SP: Martins Fontes.

Foucault, M. (1979b). Microfísica do poder. Rio de Janeiro, RJ: Edições Graal.

Foucault, M. (1980). Power/knowledge: selected interviews and other writings, 1972-1977. New York, NY: Pantheon.

Foucault, M. (1999) Em defesa da sociedade. São Paulo, SP: Martins Fontes.

Foucault, M. (2008). O nascimento da biopolítica. São Paulo, SP: Martins Fontes.

Foucault, M. (2010). Omnes et singulatium: uma crítica da razão política. In M. Motta (Org), Estratégia saber-poder (Coleção Ditos e escritos, Vol. 4). Rio de Janeiro, RJ: Forense-Universitária.

Gordon, C. (1991). Governamental rationality: an introduction. In G. Burchell, C. Gordon, \& P. Miller, (Eds.), The Foucault effect: studies in governmentality. Hemel Hampstead: Harvester Wheatsheaf.

Kalleberg, A. L. (2000). Nonstandard employment relations: part-time, temporary and contract work. Annual Review of Sociology, 26, 341-65. doi:10.1146/annurev.soc.26.1.341

Knights, D., \& Willmott, H. (2007). Socialization, yes. Skill upgrading, probably.robust theory of the capitalist labour process, no. Organization Studies, 28(9), 1369-1378. doi:10.1177/0170840607080746

Lincoln, J. R., \& Kalleberg, A. L. (1990). Culture, control and commitment. Cambridge: Cambridge University Press.

Minayo, M. C. S., Deslandes, S. F., \& Gomes, R. (2007). Pesquisa social: teoria, método e criatividade. Petrópolis, RJ: Vozes.

Mintzberg, H. (1992). El poder en la organización. Barcelona: Ariel.
Montes Cató, J. (2005). Subordinación y dominación en los espacios de trabajo: estudio soe la disciplina y sus formas de expresión. Athenea Digital, 8, 50-71. doi:10.5565/rev/athenead/vln8.219

Pedinielli, J., \& Fernandez, L. (2011). Observation clinique etl'étude de cas. Paris: Armand Colin.

Powell, T. C. (2001). Competitive advantage: logical and philosophical considerations. Strategic Management Journal, 22(9), 875-888. doi:10.1002/smj.173

Robbins, S. P. (2005). Comportamento organizacional. São Paulo, SP: Pearson Prentice Hall.

Rodriguez, E. (2006). Simulacro, subjetividad y biopolitica: de Foucault a Baudrillard. Vestigium, 1(2), 53-76. Recuperado de https://dialnet.unirioja. es/servlet/articulo?codigo $=1703769$

Sennett, R. (2006). A cultura do novo capitalismo. Rio de Janeiro, RJ: Record.

Sewell, G. (1998). The discipline of teams: the control of team-based industrial work through eletronic and peer surveillance. Administration Science Quarterly, 43(2), 397-428. doi:10.2307/2393857

Sewell, G., \& Wilkinson, B. (1992). Someone to watch over me: surveillance, discipline and the just-in-time labour process. Sociology, 26(2), 271-289. doi:10.1177/0038038592026002009

Stecher, A. (2009). La competencia por El éxito y la búsqueda de La autenticidad: modelos de identidad em el Chile actual. Psicoperspectivas, 8(2), 266-292. Recuperado de http://www.psicoperspectivas.cl/index. $\mathrm{php} / \mathrm{psicoperspectivas/article/view/67}$

Stecher, A., Godoy, L., \& Toro, J. P. (2010). Condiciones y experiencias de trabajo em la sala de venta de un supermercado: explorando los procesos de flexibilización laboral en el sector del retail en Chile. Polis (Santiago), 9(27), 523-550. doi:10.4067/S0718-65682010000300024

Weber, M. (1992). Metodologia das ciências sociais. São Paulo, SP: Cortez.

Yela Goméz, J. A., \& Hidalgo Romero, C. I. (2010). El poder en Foucault: bases analíticas para El estudio de lãs organizaciones. Cuardernos de Administración, 26(44), 57-70. Recuperado de http://cuadernosdeadministracion.univalle.edu.co/index.php/cuadernosadmin/article/view/641/2555

Yin, R. K. (2005). Estudo de caso: planejamento e métodos. Porto Alegre, RS: Bookman.

Zangaro, M. (2010). Subjetividad y trabajo: el management como dispositivo de gobierno. Trabajo $y$ Sociedad, 15(16), 163-177. Recuperado de http:// 
www.scielo.org.ar/scielo.php?script=sci_arttext\&pi$\mathrm{d}=$ S1514-68712011000100010

Zizek, S. (2012). Vivendo no fim dos tempos. São Paulo, SP: Boitempo.

\section{Cláudia Maria Perrone}

Doutora em Linguística pela Pontifícia Universidade Católica do Rio Grande do Sul (PUC/RS). Professora do Departamento de Psicologia da Universidade Federal de Santa Maria (UFSM), Santa Maria - RS. Brasil.

E-mail: cmperrone@ig.com.br

\section{Anelise Schaurich dos Santos}

Doutoranda do Programa de Pós-graduação em Psicologia da Universidade do Vale do Rio dos Sinos (PPGP/UNISINOS), bolsista CAPES/PROSUP, São Leopoldo - RS. Brasil.

E-mail: anelise_ssantos@hotmail.com

\section{Gênesis Marimar Rodrigues Sobrosa}

Doutoranda do Programa de Pós-graduação em Psicologia da Universidade do Vale do Rio dos Sinos (PPGP/UNISINOS), bolsista CAPES/PROSUP. Professora dos cursos de Administração, Tecnólogo em Gestão de Recursos Humanos e Pedagogia da Faculdade Murialdo (FAMUR), Caxias do Sul - RS. Brasil.

E-mail: genesispsi2017@gmail.com

\section{Lize Maria Cardoso Calvano}

Mestranda do Programa de Pós-graduação em Psicologia da Universidade Federal de Santa Maria (PPGP/UFSM), Santa Maria - RS. Brasil.

E-mail: lize_calvano@hotmail.com

Endereço para envio de correspondência: Universidade Federal de Santa Maria. Departamento de Psicologia. Avenida Roraima, 1000, prédio 74B, $3^{\circ}$ andar, sala 3302. Cidade Universitária. Bairro Camobi. CEP: 97105-900.

Santa Maria, RS, Brasil.

Recebido: $31 / 07 / 2014$

Reformulado: 10/11/2015

Aprovado: 01/04/2016

Received: $07 / 31 / 2014$

Reformulated: $11 / 10 / 2015$

Approved: 04/01/2016

Recibido: $31 / 07 / 2014$

Reformulado: 10/11/2015

Aceptado: 01/04/2016

Como citar: Perrone, C. M., Santos, A. S., Sobrosa, G. M. R., \& Calvano, L. M. C. (2016). Novas modulações do controle organizacional: um estudo de caso. Psicologia: Ciência e Profissão, 36(2): 389-400. doi:10.1590/1982-3703001162014

How to cite: Perrone, C. M., Santos, A. S., Sobrosa, G. M. R., \& Calvano, L. M. C. (2016). New modulations of organizational control: a case study. Psicologia: Ciência e Profissão, 36(2):389-400. doi:10.1590/1982-3703001162014

Cómo citar: Perrone, C. M., Santos, A. S., Sobrosa, G. M. R., \& Calvano, L. M. C. (2016). Nuevas modulaciones del control organizacional: un estudio de caso. Psicologia: Ciência e Profissão, 36(2): 389-400. doi:10.1590/1982-3703001162014 